\title{
Effects of Health and Longevity on Financial Risk Tolerance
}

\author{
James K. Hammitt ${ }^{\mathrm{a}, \mathrm{b}}$, Kevin Haninger ${ }^{\mathrm{c}}$ and Nicolas Treich $^{\mathrm{b}}$ \\ ${ }^{a}$ Harvard University (Center for Risk Analysis), 718 Huntington Avenue, Boston, MA 02115, \\ U.S.A. \\ E-mail: jkh@harvard.edu \\ ${ }^{\mathrm{b}}$ Toulouse School of Economics (LERNA, INRA), Manufacture des Tabacs, 21 allée de Brienne, \\ 31042 Toulouse, France. \\ E-mail: ntreich@toulouse.inra.fr \\ ${ }^{c}$ U.S. Environmental Protection Agency, 1200 Pennsylvania Avenue, NW, Room 3417G, EPA \\ West, Mail Code 5101T, Washington, D.C. 20460, U.S.A. \\ E-mail: haninger.kevin@epa.gov
}

We investigate the effects of health and life expectancy on tolerance of financial risk. Using a standard life-cycle model, we find that the effects of health and life expectancy on preferences over lifetime-income risk are theoretically ambiguous. However, risk tolerance is independent of health and life expectancy when utility takes one of the standard (harmonic absolute risk aversion) functional forms or when optimal consumption is constant over time. Our empirical results, using data from a stated-preference survey $(n=2,795)$, suggest that financial risk tolerance is positively associated with both health and life expectancy; hence utility is not consistent with standard functional forms.

The Geneva Risk and Insurance Review (2009) 34, 117-139. doi:10.1057/grir.2009.6

Keywords: risk tolerance; health; longevity; life-cycle model; consumption; stated preference

\section{Introduction}

Health and life expectancy have received little attention in economic models of consumption and financial risk taking. Although background financial risk has been shown to decrease tolerance of additional financial risks, an effect that is now well understood both theoretically (Pratt and Zeckhauser, 1987; Kimball, 1993; Gollier and Pratt, 1996; Gollier, 2001) and empirically (Guiso et al., 1996; Guiso and Paiella, 2001), risks to health and life do not necessarily have analogous effects. Understanding the effects of health and anticipated longevity on tolerance of financial risk is important for understanding a wide range of investment, retirement, and other decisions.

We design and conduct a stated-preference survey to relate health and longevity to financial risk tolerance. The survey was completed by 2,795 
randomly selected adults in the United States. Our empirical results suggest that tolerance of risk to income is positively related to both health and expected longevity.

In the following section, we describe the theoretical background for the study. First, we examine the possible effects of health and longevity on preferences for risk to lifetime income. Using a simple life-cycle consumption model we demonstrate that these effects are generally ambiguous and identify some special cases in which risk tolerance is independent of health and longevity. This theoretical model is the basis for the survey instrument and empirical models that describe how financial risk tolerance depends on health and longevity. The following sections describe the survey instrument and sample, report the results of tabulations and regression models relating risk tolerance to health, life expectancy, and other respondent characteristics, and present conclusions.

\section{Theoretical background}

We present some basic theoretical insights concerning the effects of health and life expectancy on financial risk tolerance. We consider a standard life-cycle consumption model in which an individual chooses the optimal consumption path for an exogenously determined trajectory of health and longevity. We derive an indirect lifetime utility function of per-period income and examine the Arrow-Pratt measure of risk tolerance of this indirect utility function. The effects of health and longevity on tolerance of income risk are examined and discussed.

\section{Effect of life expectancy on financial risk tolerance}

We begin by considering the effect of life expectancy on financial risk tolerance. Some scholars have suggested that younger people should be more tolerant of risks to income because of a time-diversification effect (Wilson, 1968; Gollier, 2001; Gollier, 2002). Younger people generally have more years left to live allowing them to spread consumption over a longer period of time. For example, suppose an individual loses $\$ 1,000$ and has 10 years left to live. If the individual perfectly smoothes consumption over his remaining lifetime the reduction in consumption is $\$ 100$ per year. If the individual has only 1 year left to live the reduction in consumption is $\$ 1,000$ in the remaining year. Assuming that the utility of consumption is strictly concave, an individual who loses $\$ 100$ of consumption per year for 10 years will suffer a smaller loss in total utility than if he loses $\$ 1,000$ of consumption in a single year. As a result, younger 
people can more easily absorb losses because they can smooth consumption and hence may be more willing to accept a financial risk.

If the risk to income depends on the number of years left to live, there is an additional effect. For example, suppose an individual faces a risk of losing $\$ 1,000$ every year for the rest of his life (the annual losses are perfectly correlated) as opposed to a risk of losing $\$ 1,000$ in only the first year. Because they generally have more years left to live, younger people would face a greater risk to lifetime income. The variance of the risk to lifetime income is 100 times greater if an individual lives 10 years compared to 1 year (neglecting a discount rate effect). ${ }^{1}$ Similarly, if risks to annual income are positively but not perfectly correlated, younger individuals will face greater lifetime risk. As a result, younger people may be less willing to accept a risk that affects income in every future year of their lives.

The total effect of longevity on tolerance of income risk thus depends on two opposite effects, the time-diversification effect and the lifetime-income effect. We examine the strength of these two effects in a simple life-cycle consumption model. Suppose an individual receives a common per-period income $y$ over his remaining lifetime. Implicitly, risks to income in each period are perfectly correlated and uncertainty about per-period income is resolved in the first period. For example, an individual entering the labour market may be uncertain about his labour productivity and wage but much of this uncertainty may be resolved early in his career. ${ }^{2}$

Consider an expected indirect lifetime utility function $v(y)$ obtained by maximizing a standard, intertemporally additive utility function (Yaari, 1965) subject to a budget constraint:

$$
\begin{gathered}
v(y)=\max _{C} \sum_{t=0}^{T} s_{t} \beta^{t} u\left(c_{t}\right) \\
\sum_{t=0}^{T} \rho^{t} s_{t} c_{t}=\sum_{t=0}^{T} \rho^{t} s_{t} y .
\end{gathered}
$$

$\beta$ is a non-negative utility discount factor, $s_{t}$ is the exogenous probability of surviving through period $t, u(\cdot)$ is the instantaneous utility of consumption

\footnotetext{
${ }^{1}$ This relates to Samuelson's argument concerning the fallacy of the law of large numbers (Samuelson, 1963) and to long-standing debates about time diversification in dynamic risky portfolio allocation. See Gollier (2001) and Karlsson (2006) for recent summaries of the theoretical and empirical arguments.

${ }^{2}$ Eeckhoudt et al. (2005) examine the effects of differences in the timing of resolution of uncertainty about lifetime income.
} 
120

$c_{t}$ in period $t$ (assumed to be positive, strictly increasing, concave, and threetimes differentiable), $C$ is the vector of consumption in each period $\left[c_{0}, c_{1}, \ldots, c_{T}\right]$, and $T$ is longevity. The budget constraint (2) incorporates an assumption that the individual can save or borrow at actuarially fair rates associated with a market discount factor $\rho$ (equal to the reciprocal of one plus a constant interest rate).

Suppose that the individual perfectly smoothes consumption over his remaining lifetime such that consumption $c_{t}$ equals current per-period income $y$ in each period. Eq. (1) simplifies to

$$
v(y)=\left[\sum_{t=0}^{T} s_{t} \beta^{t}\right] u(y) .
$$

Observe in Eq. (3) that $v(y)$ is a linear function of $u(y)$ and so it has exactly the same risk tolerance. When calculating the Arrow-Pratt measure of risk tolerance of $v(y)$, that is, $-v^{\prime}(y) / v^{\prime \prime}(y)$, the term in brackets vanishes leaving

$$
-\frac{v^{\prime}(y)}{v^{\prime \prime}(y)}=-\frac{u^{\prime}(y)}{u^{\prime \prime}(y)} \text {. }
$$

As a result, when the individual perfectly smoothes consumption the timediversification and lifetime-income effects cancel and there is no effect of longevity on tolerance of income risk. ${ }^{3}$

The result that longevity has no effect on risk tolerance depends on the assumption that the individual perfectly smoothes consumption over his remaining lifetime. To illustrate, assume the individual will live for two periods with certainty. His lifetime utility function can be expressed as

$$
v(y)=\max _{c}\{u(c)+\beta u[y+R(y-c)]\}
$$

where $R$ is an interest factor (equal to $1 / \rho$ ). Optimal consumption $c^{*}$ is defined by the first order condition ${ }^{4}$

$$
u^{\prime}\left(c^{*}\right)=\beta R u^{\prime}\left[y+R\left(y-c^{*}\right)\right]
$$

\footnotetext{
${ }^{3}$ Bommier and Rochet (2006) show that risk tolerance may depend on life expectancy if preferences for consumption are not additively separable across periods, even if consumption is perfectly smooth.

${ }^{4}$ When the utility discount rate equals the interest rate (i.e., $\beta=\rho$ ), the model reduces to the case in which the individual perfectly smoothes consumption over his remaining lifetime.
} 
Solving for the risk tolerance of $v(y)$ yields

$$
-\frac{v^{\prime}(y)}{v^{\prime \prime}(y)}=-\frac{u^{\prime}\left(c^{*}\right)}{u^{\prime \prime}\left(c^{*}\right)} \frac{1}{\partial c^{*}} .
$$

Differentiating Eq. (6) with respect to $y$ and rearranging terms yields

$$
\frac{\partial c^{*}}{\partial y}=\frac{\beta R(1+R) u^{\prime \prime}\left[y+R\left(y-c^{*}\right)\right]}{u^{\prime \prime}\left(c^{*}\right)+\beta R^{2} u^{\prime \prime}\left[y+R\left(y-c^{*}\right)\right]}=\frac{(1+R) \tau\left(c^{*}\right)}{R \tau\left(c^{*}\right)+\tau\left[y+R\left(y-c^{*}\right)\right]}
$$

where $\tau(\cdot)$ denotes the local risk tolerance of $u(\cdot),-u^{\prime}(\cdot) / u^{\prime \prime}(\cdot)$. After substituting Eq. (8) into Eq. (7), the risk tolerance of $v(y)$ can be expressed as

$$
-\frac{v^{\prime}(y)}{v^{\prime \prime}(y)}=\frac{R \tau\left(c^{*}\right)+\tau\left[y+R\left(y-c^{*}\right)\right]}{1+R} .
$$

The risk tolerance of lifetime utility is a weighted average of the risk tolerance of instantaneous utility computed at the consumption levels in each period. From Eq. (9), it is clear by Jensen's inequality that

$$
-\frac{v^{\prime}(\cdot)}{v^{\prime \prime}(\cdot)} \geqslant \tau(\cdot) \text { iff } \tau(\cdot) \text { is convex. }
$$

To summarize, an individual living for one period would have lifetime utility $v(\cdot)$ equal to instantaneous utility $u(\cdot)$. Living two periods as opposed to one increases the risk tolerance of lifetime utility if and only if $\tau(\cdot)$ is convex. Longevity may affect the willingness to accept a lifetime risk on income, but the direction of the effect depends on the convexity of the risk tolerance of the instantaneous utility function.

It is difficult to predict whether risk tolerance is more likely to be convex or concave. Risk tolerance is linear in income if and only if the utility function belongs to the class of utility functions exhibiting harmonic absolute risk aversion (HARA). The HARA class includes all familiar parametric utility functions, such as quadratic, exponential, power, and logarithmic forms (Gollier, 2001).

\section{Effect of health on financial risk tolerance}

We now examine the effect of health on risk tolerance. There are several pathways through which health may affect willingness to accept a risk on lifetime income. First, health may affect the marginal utility of consumption and, more generally, the shape of the instantaneous utility function. Second, health influences life expectancy and thus affects the expected values of both 
future consumption and future earnings. Third, health may affect productivity and flexibility to adapt and thus affect future income. Fourth, health affects medical expenditures, thereby influencing the budget available for consuming other goods.

A thorough examination of these effects and their interrelations is crucial for understanding the dynamics of consumption patterns, retirement and other decisions (e.g., Benitez-Silva and Dwyer, 2005). However, we are interested in a tangential and arguably more fundamental question, the effect of health on financial risk tolerance. The elucidation of these other effects is beyond the scope of this paper but we offer some comments before continuing. The effect of health on life expectancy is related to the effect of longevity discussed above. ${ }^{5}$ The effect of health on medical expenditures may be negligible if the individual has full health insurance the cost of which is independent of his health (e.g., public health insurance). The effect of health on future income may be ignored if the individual is assumed to have a constant income over his lifetime, perhaps through disability insurance. ${ }^{6}$

In the following discussion, we restrict our attention to the first effect of health, namely, the effect of health on the instantaneous utility of consumption. We assume that instantaneous utility $u\left(c_{t}, h_{t}\right)$ depends on both current consumption $c_{t}$ and health status $h_{t}$.

Specification of the instantaneous utility function for health and consumption is an open question and depends on the measurement of health (e.g., Hammitt, 2002b; Rey and Rochet, 2004). Most life-cycle consumption models ignore health status, which is recognized as an important limitation (Engen et al., 1999). For simplicity, we assume that the utility function exhibits a multiplicative relationship between health status and consumption, ${ }^{7}$

$$
u\left(c_{t}, h_{t}\right)=h_{t} u\left(c_{t}\right) .
$$

${ }^{5}$ Our empirical analysis controls for longevity when analyzing the effect of health on risk tolerance.

${ }^{6}$ The survey asks participants to assume that they will receive a constant income every year for life.

${ }^{7}$ This multiplicative relationship is often assumed, for example, Garber and Phelps (1997), Bleichrodt and Quiggin (1999), Murphy and Topel (2006). Discussion of the multiplicative specification within life-cycle consumption models may be found in Palumbo (1999) and Domeij and Johannesson (2006). Domeij and Johannesson (2006) and Murphy and Topel (2006) argue that the multiplicative specification is consistent with observations that consumption declines with age, making consumption at older ages less desirable. In addition, the multiplicative specification is consistent with life-cycle models based on quality-adjusted life years (Bleichrodt and Quiggin, 1999). Shepard and Zeckhauser (1984) and Smith and Keeney (2005) also analyze life-cycle consumption models with uncertain survival. 
We assume, without loss of generality, that $h$ is scaled so that $h=1$ corresponds to full health (consistent with the measurement of health used in constructing quality-adjusted life years; Hammitt, 2002a). We further assume that $h \geqslant 0$ so the marginal utility of consumption is non-negative for all health states. The multiplicative specification implies that the marginal utility of consumption increases with health status, that is, incremental consumption is more desirable when health is good than when health is poor. Intuitively, complementarity between consumption and health seems plausible, as many activities are enjoyable only when health is sufficiently good. Viscusi and Evans (1990), Sloan et al. (1998), and Finkelstein et al. (2008) report empirical evidence that the marginal utility of consumption increases with health. $^{8}$

We begin with the simplest case, the one-period model. In this model, lifetime utility is equal to the product of current health status and the utility function of income,

$$
v(y)=h u(y) .
$$

The multiplicative specification implies that risk tolerance is independent of health. ${ }^{9}$

Returning to the standard multiperiod model in Eq. (1), the lifetime utility function can be expressed as

$$
v(y)=\max _{C} \sum_{t=0}^{T} s_{t} \beta^{t} h_{t} u\left(c_{t}\right)
$$

subject to the budget constraint (2). Recognizing that future health is uncertain, we can interpret $h_{t}$ as the exogenously determined expected value of the random health state $\tilde{h}_{t}$ if we assume the individual must choose $c_{t}$ before obtaining any information that would allow him to update his estimate of $\tilde{h}_{t}$. For example, $\tilde{h}_{t}$ may be conditionally independent of health in prior periods or

\footnotetext{
${ }^{8}$ In contrast, Evans and Viscusi (1991) find that short-term illness may increase the marginal utility of consumption and Lillard and Weiss (1997) report that adverse health shocks increase the marginal utility of consumption among elderly households. Edwards (2008) observes a similar empirical relationship and shows in a dynamic portfolio choice model that this relationship may lead individuals to reduce the shares of their portfolios in risky assets as health risk increases.

${ }^{9}$ Note that risk tolerance is not necessarily independent of health when the specification is not multiplicative. For example, let $u\left(c_{t}, h_{t}\right)=\log \left[c_{t}-m\left(1-h_{t}\right)\right]$ where $m(1-h)$ is the monetary value of a health decrement. Then local risk tolerance equals $c_{t}-m\left(1-h_{t}\right)$ which depends on health.
} 
the individual may be required to choose the consumption vector $C$ at the start of the initial period.

Specifying health status $h_{t}$ as a function of time requires some additional assumptions to obtain comparative-static results concerning the effect of health on risk tolerance. We begin by supposing, as in the analysis of longevity, that the individual perfectly smoothes consumption over his remaining lifetime so that consumption $c_{t}$ equals current per-period income $y$ in each period. The multiplicative specification of the instantaneous utility function in Eq. (11) implies that the expected present value of the path of health status $h_{t}$ will cancel when computing the risk tolerance of lifetime utility, and thus health will have no effect on risk tolerance.

Health may affect risk tolerance when the individual does not perfectly smooth consumption. To illustrate, return to the simple two-period model (5). As before, we assume that the individual lives for two periods with certainty and can save or borrow against future income at a common interest rate such that the lifetime utility function can be expressed as

$$
v(y)=\max _{c}\left\{h_{1} u(c)+\beta h_{2} u[y+R(y-c)]\right\}
$$

where optimal consumption $c^{*}$ is now defined by the first-order condition

$$
u^{\prime}\left(c^{*}\right)=\beta R\left(\frac{h_{2}}{h_{1}}\right) u^{\prime}\left[y+R\left(y-c^{*}\right)\right] .
$$

Solving for the risk tolerance of $v(y)$ yields

$$
-\frac{v^{\prime}(y)}{v^{\prime \prime}(y)}=\frac{R \tau\left(c^{*}\right)+\tau\left[y+R\left(y-c^{*}\right)\right]}{1+R}
$$

with $c^{*}$ defined by Eq. (15). Differentiating Eq. (16) with respect to health status in period $t, h_{t}$, yields

$$
\frac{\partial}{\partial h_{t}}\left[-\frac{v^{\prime}(y)}{v^{\prime \prime}(y)}\right]=\frac{R}{1+R}\left\{\tau^{\prime}\left(c^{*}\right)-\tau^{\prime}\left[y+R\left(y-c^{*}\right)\right]\right\} \frac{\partial c^{*}}{\partial h_{t}} .
$$

It can be verified from the first-order condition in Eq. (15) that $\partial c^{*} / \partial h_{1}$ is always positive and $\partial c^{*} / \partial h_{2}$ is always negative. Hence, the effect of health on risk tolerance depends on the sign of the bracketed term on the right-hand side of Eq. (17). Observe that this sign depends on the curvature of $\tau(\cdot)$ and whether $c^{*}$ is smaller or larger than $y$. If $\tau(\cdot)$ is linear the bracketed term simplifies to zero. The bracketed term also simplifies to zero when $c^{*}$ equals $y$. 
Hence, if the risk tolerance of instantaneous utility is linear (i.e., if the utility function is HARA), or if the individual perfectly smoothes consumption over his remaining lifetime, then health will have no effect on willingness to accept a risk on lifetime income. Perfect smoothing of consumption is optimal if $\beta R=h_{1} / h_{2}$. If health declines with age, this condition is consistent with the reasonable assumption that the utility discount rate is less than the interest rate (i.e., $\beta R>1$ ).

Another possibility is to assume a specific functional form for health status $h_{t}$. Consider a simple power form, $h_{t}=h^{t}$, as in Nordhaus (2002). ${ }^{10}$ In this case, the lifetime utility function simplifies to

$$
v(y)=\max _{C} \sum_{t=0}^{T} s_{t} \beta^{t} h^{t} u\left(c_{t}\right)
$$

subject to the budget constraint (2). Eq. (18) shows that the health status decay factor $h$ plays an equivalent role to that of the discount factor $\beta$. In this model as well, health has no effect on willingness to accept a risk on lifetime income if $\tau(\cdot)$ is linear.

Before turning to the empirical analysis, let us summarize the theoretical results. We have examined the effects of health and longevity on willingness to accept a risk to lifetime income. This amounts to examining the effects of health and longevity on the risk tolerance of lifetime utility. Even in a simple life-cycle consumption model, these effects are generally ambiguous. An exception occurs when the individual perfectly smoothes consumption over his remaining lifetime, a benchmark case in which health and longevity never affect risk tolerance. More importantly, we have shown that for the standard parametric utility functions used in the economics literature (i.e., HARA utility functions), health and longevity do not affect risk tolerance in the standard intertemporal model, even if the individual does not perfectly smooth consumption. Hence, the empirical analysis that follows may be viewed as a test for the standard specifications of the utility function.

\section{Survey}

We design and conduct a stated-preference survey to relate health and longevity to risk tolerance. This section describes the survey instrument and sample.

\footnotetext{
${ }^{10}$ This model implies a convex decreasing relationship between age and health. The typical pattern is declining but perhaps more likely to be concave than convex.
} 


\section{Survey instrument}

The survey includes questions that measure health, longevity, and financial risk tolerance. Respondents assess their health using three measures: a standard categorical scale, a visual analogue scale (VAS), and the Health Utilities Index Mark 3 (HUI). The categorical scale describes health as "excellent," "very good," "good," "fair," or "poor." The VAS is a numbered line with endpoints of 0 and 100 labelled "equivalent to dead" and "perfect health," respectively. The HUI is a generic, preference-based, multiattribute health-status classification system and index that is widely used as a measure of health-related quality of life in clinical studies, population health surveys, and to estimate qualityadjusted life years for economic evaluation (Feeny et al., 2002). The HUI classifies health according to the degree of functional impairment on eight dimensions: vision, hearing, speech, ambulation, dexterity, emotion, cognition, and pain. For each dimension of health, there are five or six levels of functional impairment that range from complete function to severe impairment. The HUI assigns values less than zero to health states that are perceived to be worse than dead.

After assessing their current health, respondents complete two dichotomouschoice questions that measure preferences for gambles on lifetime income. The questions are based on those used to measure risk tolerance in Wave I of the Health and Retirement Study and have been shown to be predictive of a range of investment, insurance, employment, and health behaviours (Barsky et al., 1997; Picone et al., 2004). ${ }^{11}$ The first question asks respondents to make a hypothetical choice between two jobs. The first job pays respondents their current income each year for life. The second job involves a 50-50 gamble in which respondents are paid either twice their current income each year for life or a fraction of their current income each year for life. The first question reads as follows:

Suppose that you are the only income earner in the family and that you have a good job guaranteed to give you your current income every year for life. You are given the opportunity to take a new and equally good job for life with a 50-50 chance that it will either double your income or cut it by a third. Would you take the new job?

${ }^{11}$ Dohmen et al. (2005) find that survey measures predict actual risk-taking behavior in a lottery field experiment, although in some contexts the response to a general question about willingness to take risks on a 0 to 10 scale is a better predictor of behavior than is the response to a hypothetical lottery question. 
If the respondent accepts the first gamble, she is asked the following question:

Suppose the chances were 50-50 that it would either double your income or cut it by half. Would you take the new job?

Alternatively, if the respondent rejects the first gamble she is asked the following question:

Suppose the chances were 50-50 that it would either double your income or cut it by a fifth. Would you take the new job?

The answers to the dichotomous-choice questions are used to place respondents into one of four groups defined by relative risk tolerance with respect to lifetime income (i.e., relative risk tolerance of $v(y)$ analyzed in Theoretical background section). ${ }^{12}$ Without assuming any particular form of the utility function, these groups can be ordered by increasing levels of relative risk tolerance as follows: Group I (reject first and second gambles), Group II (reject first and accept second gamble), Group III (accept first and reject second gamble), and Group IV (accept first and second gambles).

\section{Sample}

The survey was presented to 4,481 randomly selected adults in the United States. Respondents are members of a demographically representative panel maintained by Knowledge Networks. Respondents are recruited to the panel using random digital dialling and provided free internet access and hardware, such as MSN $^{\circledR}$ TV, as an incentive for participation. In total, 2,795 interviews were completed between August and October 2004 yielding a response rate of 62 per cent. We exclude 39 respondents who did not answer the risk-tolerance questions, three respondents who did not complete the HUI, and two respondents who did not rate their health using the categorical scale. A total of 2,751 respondents are included in the analysis.

\section{Results}

This section summarizes respondent characteristics and reports estimates of how relative risk tolerance depends on health, longevity, and other respondent characteristics.

\footnotetext{
${ }^{12}$ Note that the theoretical effects of longevity and health on relative risk tolerance, $-v^{\prime}(y) / v^{\prime \prime}(y)$, are the same as those for absolute risk tolerance, $-v^{\prime}(y) / v^{\prime \prime}(y)$, addressed in Theoretical background section.
} 


\section{Respondent characteristics}

Table 1 lists the variables used for analysis with the means, standard deviations, and ranges for the sample of 2,751 respondents. Mean age is 45 years with a range of 18-96 years. Forty-seven per cent of respondents are

Table 1 Variables and descriptive statistics

\begin{tabular}{|c|c|c|c|}
\hline Variable & Mean & Std. dev. & Range \\
\hline \multicolumn{4}{|l|}{ Relative risk-tolerance group } \\
\hline I. Reject first and second gambles & 0.539 & 0.499 & {$[0,1]$} \\
\hline II. Reject first and accept second gambles & 0.153 & 0.360 & {$[0,1]$} \\
\hline III. Accept first and reject second gambles & 0.153 & 0.360 & {$[0,1]$} \\
\hline IV. Accept first and second gambles & 0.155 & 0.362 & {$[0,1]$} \\
\hline Life expectancy & 35.736 & 14.172 & {$[3,63]$} \\
\hline \multicolumn{4}{|l|}{ Health category } \\
\hline Excellent & 0.116 & 0.320 & {$[0,1]$} \\
\hline Very good & 0.351 & 0.477 & {$[0,1]$} \\
\hline Good & 0.361 & 0.480 & {$[0,1]$} \\
\hline Fair & 0.142 & 0.349 & {$[0,1]$} \\
\hline Poor & 0.030 & 0.170 & {$[0,1]$} \\
\hline Visual analogue scale score & 0.762 & 0.169 & {$[0,1]$} \\
\hline Health-utilities index score & 0.800 & 0.214 & {$[-0.316,1]$} \\
\hline Age & 44.864 & 16.239 & {$[18,96]$} \\
\hline Male & 0.474 & 0.499 & {$[0,1]$} \\
\hline \multicolumn{4}{|l|}{ Race and ethnicity } \\
\hline White, non-Hispanic & 0.728 & 0.445 & {$[0,1]$} \\
\hline Hispanic & 0.122 & 0.328 & {$[0,1]$} \\
\hline Black, non-Hispanic & 0.106 & 0.308 & {$[0,1]$} \\
\hline Other, non-Hispanic & 0.044 & 0.204 & {$[0,1]$} \\
\hline College degree & 0.254 & 0.435 & {$[0,1]$} \\
\hline Household income in thousands of dollars & 47.739 & 35.892 & {$[1,200]$} \\
\hline \multicolumn{4}{|l|}{ Distribution of household income } \\
\hline Less than $\$ 20,000$ & 0.211 & 0.408 & {$[0,1]$} \\
\hline$\$ 20,000-35,000$ & 0.205 & 0.404 & {$[0,1]$} \\
\hline$\$ 35,000-50,000$ & 0.206 & 0.405 & {$[0,1]$} \\
\hline$\$ 50,000-75,000$ & 0.201 & 0.401 & {$[0,1]$} \\
\hline More than $\$ 75,000$ & 0.177 & 0.381 & {$[0,1]$} \\
\hline Married & 0.541 & 0.498 & {$[0,1]$} \\
\hline Child in household & 0.388 & 0.487 & {$[0,1]$} \\
\hline Household size & 2.614 & 1.389 & {$[1,10]$} \\
\hline Head of household & 0.826 & 0.379 & {$[0,1]$} \\
\hline Home ownership & 0.651 & 0.477 & {$[0,1]$} \\
\hline
\end{tabular}


male. Seventy-three per cent of respondents identify themselves as nonHispanic White, 12 per cent as Hispanic, 11 per cent as non-Hispanic Black, and 4.4 per cent as none of these categories. Twenty-five per cent of respondents have a college degree. Mean household income is $\$ 47,700$, with 21 per cent of households earning annual incomes less than $\$ 20,000,21$ per cent earning $\$ 20,000-35,000,21$ per cent earning $\$ 35,000-50,000,20$ per cent earning $\$ 50,000-75,000$, and 18 per cent earning more than $\$ 75,000$. Fifty-four per cent of respondents are married. Thirty-nine per cent live in a household with at least one child younger than 18 years. Mean household size is 2.6 persons. Eighty-three per cent of respondents identify themselves as head of household. Sixty-five per cent own their home.

With respect to preferences for gambles on lifetime income, 54 per cent of respondents are in our least risk-tolerant class, rejecting the first and second gambles, 15 per cent reject the first gamble but accept the second gamble, 15 per cent accept the first gamble but reject the second gamble, and 16 accept both gambles.

With respect to self-reported health, 12 per cent of respondents describe their health as "excellent," 35 per cent as "very good," 36 per cent as "good," 14 per cent as "fair," and 3 per cent as "poor." The mean VAS score is 0.762 with a range of $0-1$. The mean HUI score is 0.800 with a range of -0.316 to 1 . We estimate life expectancy based on age-, race-, and sex-specific life tables for the U.S. population in 2003 (Arias, 2006). Mean life expectancy is 36 years with a range of 3-63 years.

Table 2 reports the means and standard deviations of the VAS and HUI scores, stratified by health reported on the categorical scale. Within each category, the measures are similar. The mean VAS score is slightly smaller than the mean HUI score, consistent with the general finding that rating-scale scores are often smaller than standard-gamble and other choice-based measures (Torrance et al., 1996). Comparisons between VAS and HUI scores may be

Table 2 VAS and HUI scores by health category

\begin{tabular}{|c|c|c|c|c|c|}
\hline \multirow[t]{2}{*}{ Health category } & \multicolumn{2}{|c|}{$V A S$ score } & \multicolumn{2}{|c|}{ HUI score } & \multirow[t]{2}{*}{ Number of respondents } \\
\hline & Mean & Std. dev. & Mean & Std. dev. & \\
\hline Excellent & 0.929 & 0.081 & 0.932 & 0.095 & 319 \\
\hline Very Good & 0.854 & 0.080 & 0.886 & 0.129 & 965 \\
\hline Good & 0.726 & 0.115 & 0.790 & 0.174 & 994 \\
\hline Fair & 0.570 & 0.163 & 0.595 & 0.260 & 391 \\
\hline Poor & 0.385 & 0.157 & 0.363 & 0.277 & 82 \\
\hline
\end{tabular}

Note: Possible scores for the VAS range are between 0 and 1, while possible scores for the HUI range are between -0.359 and 1 . 
affected by the difference in range: the VAS scores are constrained between 0 and 1 while possible scores for the HUI range are between -0.359 and 1 .

\section{Effect of life expectancy on risk tolerance}

Table 3 reports the percentage of respondents within each risk-tolerance group, stratified by age, life expectancy, health category, VAS score, and HUI score. The table also shows the combined percentage of respondents who reject the first gamble on lifetime income (i.e., groups I and II), allowing comparison with results based on the responses to both dichotomous-choice questions.

Examining the distribution of respondents across the four risk-tolerance groups, we find that risk tolerance decreases with age, based on a two-sided Jonckheere-Terpstra non-parametric test for trend $(p<0.001)$. These results are similar to those reported by Barsky et al. (1997) who examined risk tolerance among respondents most of whom were between the ages of 51 and 61 years. ${ }^{13}$ Analysis of the responses to only the first question reveals a similar relationship, based on a two-sided Cochran-Armitage test for trend $(p<0.001)$. Similarly, we observe a negative, statistically significant Spearman correlation coefficient between risk-tolerance group and age $(\rho=-0.138, p<0.001)$.

The second panel of the table reports the results by life expectancy, which is strongly negatively correlated with age $(r=-0.983, p<0.001)$. Not surprisingly, a two-sided Jonckheere-Terpstra non-parametric test for trend based on the responses to both dichotomous-choice questions and a two-sided Cochran-Armitage test for trend based on only the responses to the first question confirm that risk tolerance increases with life expectancy $(p<0.001)$. We also observe a positive, statistically significant Spearman correlation coefficient between risk-tolerance group and life expectancy $(\rho=0.123$, $p<0.001)$.

\section{Effect of health on risk tolerance}

The third panel of Table 3 reports results by self-reported health category. Examining the distribution of respondents across the four risk-tolerance groups we find that risk tolerance increases with better health, based on a twosided Jonckheere-Terpstra non-parametric test for trend $(p=0.007)$. Although responses to the first question suggest a similar relationship, we are unable to reject the null hypothesis that the proportion of respondents who decline the

\footnotetext{
${ }^{13}$ Barsky et al. (1997) report results from Wave I of the Health and Retirement Study (HRS). The HRS surveyed individuals between the ages of 51 and 61 years and their spouses (some of whom were outside the targeted age range).
} 
Table 3 Risk tolerance by age, life expectancy, health category, VAS score, and HUI score

\begin{tabular}{|c|c|c|c|c|c|c|}
\hline \multirow{2}{*}{$\begin{array}{l}\text { Respondent } \\
\text { characteristic }\end{array}$} & \multicolumn{5}{|c|}{ Percentage of respondents by risk-tolerance group } & \multirow{2}{*}{$\begin{array}{l}\text { Number of } \\
\text { respondents }\end{array}$} \\
\hline & $\begin{array}{l}\text { I. Reject } \\
\text { first and } \\
\text { second } \\
\text { gambles }\end{array}$ & $\begin{array}{l}\text { II. Reject } \\
\text { first and } \\
\text { accept second } \\
\text { gambles }\end{array}$ & $\begin{array}{l}\text { III. Accept } \\
\text { first and } \\
\text { reject second } \\
\text { gambles }\end{array}$ & $\begin{array}{l}\text { IV. Accept } \\
\text { first and } \\
\text { second } \\
\text { gambles }\end{array}$ & $\begin{array}{c}\text { I. and II. } \\
\text { Reject } \\
\text { first gamble }\end{array}$ & \\
\hline \multicolumn{7}{|l|}{ Age (years) } \\
\hline $18-24$ & 42.9 & 18.8 & 15.7 & 22.6 & 61.7 & 261 \\
\hline $25-34$ & 45.6 & 18.2 & 18.6 & 17.6 & 63.8 & 603 \\
\hline $35-44$ & 52.8 & 17.2 & 15.5 & 14.5 & 70.0 & 587 \\
\hline $45-54$ & 56.6 & 13.4 & 14.9 & 15.1 & 70.0 & 523 \\
\hline $55-64$ & 64.3 & 12.7 & 12.0 & 11.0 & 77.1 & 401 \\
\hline $65-74$ & 60.9 & 9.1 & 15.4 & 14.6 & 70.0 & 253 \\
\hline$>74$ & 64.2 & 13.0 & 8.9 & 13.8 & 77.2 & 123 \\
\hline \multicolumn{7}{|c|}{ Life expectancy (years) } \\
\hline$<10$ & 63.3 & 14.4 & 7.8 & 14.4 & 77.8 & 90 \\
\hline $10-20$ & 62.0 & 10.5 & 14.1 & 13.3 & 72.6 & 361 \\
\hline $20-30$ & 59.6 & 14.3 & 13.9 & 12.1 & 73.9 & 545 \\
\hline $30-40$ & 55.8 & 14.9 & 14.5 & 14.8 & 70.8 & 650 \\
\hline $40-50$ & 49.3 & 15.1 & 17.4 & 18.2 & 64.4 & 570 \\
\hline $50-60$ & 43.2 & 20.8 & 17.6 & 18.4 & 64.0 & 472 \\
\hline$>60$ & 47.6 & 15.9 & 15.9 & 20.6 & 63.5 & 63 \\
\hline \multicolumn{7}{|l|}{ Health category } \\
\hline Excellent & 47.3 & 18.8 & 18.5 & 15.4 & 66.1 & 319 \\
\hline Very good & 51.1 & 18.4 & 15.2 & 15.2 & 69.5 & 965 \\
\hline Good & 57.0 & 12.3 & 15.0 & 15.7 & 69.3 & 994 \\
\hline Fair & 55.8 & 14.1 & 14.3 & 15.9 & 69.8 & 391 \\
\hline Poor & 67.1 & 6.1 & 11.0 & 15.9 & 73.2 & 82 \\
\hline \multicolumn{7}{|l|}{ VAS score } \\
\hline $0.801-1.000$ & 51.9 & 17.2 & 16.4 & 14.5 & 69.1 & 1,142 \\
\hline $0.601-0.800$ & 55.0 & 14.2 & 14.9 & 15.9 & 69.2 & 1,099 \\
\hline $0.401-0.600$ & 53.1 & 15.0 & 14.7 & 17.1 & 68.1 & 339 \\
\hline $0.201-0.400$ & 64.0 & 10.3 & 10.3 & 15.4 & 74.3 & 136 \\
\hline $0.000-0.200$ & 57.9 & 10.5 & 10.5 & 21.1 & 68.4 & 19 \\
\hline \multicolumn{7}{|l|}{ HUI score } \\
\hline $0.801-1.000$ & 51.4 & 16.8 & 15.7 & 16.1 & 68.2 & 1,719 \\
\hline $0.601-0.800$ & 53.9 & 14.6 & 16.7 & 14.8 & 68.5 & 562 \\
\hline $0.401-0.600$ & 56.1 & 14.8 & 13.0 & 16.1 & 70.9 & 230 \\
\hline $0.201-0.400$ & 69.4 & 8.3 & 9.3 & 13.0 & 77.8 & 108 \\
\hline $0.001-0.200$ & 69.6 & 10.7 & 8.9 & 10.7 & 80.4 & 56 \\
\hline$-0.359-0.000$ & 71.1 & 1.3 & 14.5 & 13.2 & 72.4 & 76 \\
\hline
\end{tabular}


first gamble on lifetime income does not vary with health category, based on a two-sided Cochran-Armitage test for trend $(p=0.278)$.

The fourth panel of Table 3 reports results by VAS score. Examining the distribution of respondents across the four risk-tolerance groups we do not find a statistically significant relationship between risk tolerance and VAS category, based on a two-sided Jonckheere-Terpstra non-parametric test for trend $(p=0.269)$. Likewise, we are unable to reject the null hypothesis that the proportion of respondents who decline the first gamble on lifetime income does not vary with VAS category, based on a two-sided Cochran-Armitage test for trend $(p=0.596)$. Finally, we observe a positive, statistically insignificant Spearman correlation coefficient between risk-tolerance group and VAS score $(\rho=0.022, p=0.255)$.

The last panel reports results by HUI score. The results suggest that risk tolerance increases with HUI score and that HUI score is a better predictor of risk tolerance than are health reported on the categorical scale or VAS. In particular, a two-sided Jonckheere-Terpstra non-parametric test for trend $(p<0.001)$ based on the responses to both dichotomous-choice questions and a two-sided Cochran-Armitage test for trend $(p=0.017)$ based on only the responses to the first question indicate that risk tolerance increases with HUI category. We observe a positive, statistically significant Spearman correlation coefficient between risk-tolerance group and HUI score $(\rho=0.079, p<0.001)$.

\section{Regression models}

Risk tolerance is modelled as a function of health, life expectancy, and other respondent characteristics. Given the ordinal response variable, we estimate ordered logistic regression models using the maximum-likelihood method with bootstrapped standard errors. The results are shown in Table 4 .

We begin by estimating separate regression models that include only variables for life expectancy or health. Model 1 indicates that risk tolerance increases with expected longevity. The estimated coefficient for life expectancy is $0.016(p<0.001)$ suggesting that each additional year of life expectancy is associated with a 1.6 per cent increase in the odds of being in a more risktolerant group. Model 2 indicates that risk tolerance increases with health. The estimated coefficient for HUI score is $0.894(p<0.001)$ suggesting that each hundredth of a point increase in HUI score is associated with a 0.9 per cent increase in the odds of being in a higher risk-tolerance group.

Model 3 contains variables for both life expectancy and health. The estimated effect of life expectancy on risk tolerance is largely unaffected by controlling for health. However, the estimated effect of health on risk tolerance is reduced by controlling for expected longevity. The estimated coefficient for life expectancy is $0.014(p<0.001)$ suggesting that each additional year of life 
Table 4 Regression results

\begin{tabular}{|c|c|c|c|c|c|}
\hline Variable & Model 1 & Model 2 & Model 3 & Model 4 & Model 5 \\
\hline Intercept: Group I vs. & $-0.748 * * *$ & $-0.879 * * *$ & $-1.195 * * *$ & $-0.865^{* * *}$ & $1.182 * * *$ \\
\hline Group II & $(0.100)$ & $(0.149)$ & $(0.164)$ & $(0.269)$ & $(0.414)$ \\
\hline Intercept: Group II vs. & $-1.409 * * *$ & $-1.536^{* * *}$ & $-1.859 * * *$ & $-1.540 * * *$ & 0.507 \\
\hline Group III & $(0.104)$ & $(0.151)$ & $(0.168)$ & $(0.271)$ & $(0.388)$ \\
\hline Intercept: Group III vs. & $-2.299 * * *$ & $-2.423 * * *$ & $-2.750 * * *$ & $-2.441 * * *$ & -0.395 \\
\hline Group IV & $(0.112)$ & $(0.158)$ & $(0.173)$ & $(0.273)$ & $(0.389)$ \\
\hline Life expectancy & $\begin{array}{l}0.016 * * * \\
(0.003)\end{array}$ & & $\begin{array}{l}0.014^{* * * *} \\
(0.003)\end{array}$ & $\begin{array}{l}0.019 * * * \\
(0.003)\end{array}$ & \\
\hline HUI score & & $\begin{array}{l}0.894^{* * *} \\
(0.177)\end{array}$ & $\begin{array}{l}0.657 * * * \\
(0.192)\end{array}$ & $\begin{array}{l}0.517 * * * \\
(0.192)\end{array}$ & $\begin{array}{l}0.500 * * \\
(0.203)\end{array}$ \\
\hline Age & & & & & $\begin{array}{l}-0.046^{* * * *} \\
(0.014)\end{array}$ \\
\hline $\operatorname{Age}^{2}$ & & & & & $\begin{array}{l}0.000 * * \\
(0.000)\end{array}$ \\
\hline Male & & & & $\begin{array}{l}0.314^{* * *} \\
(0.076)\end{array}$ & $\begin{array}{l}0.242 * * * \\
(0.073)\end{array}$ \\
\hline Black, non-Hispanic & & & & $\begin{array}{l}0.336^{* *} \\
(0.138)\end{array}$ & $\begin{array}{l}0.284 * * \\
(0.137)\end{array}$ \\
\hline Hispanic & & & & $\begin{array}{c}0.118 \\
(0.121)\end{array}$ & $\begin{array}{c}0.116 \\
(0.123)\end{array}$ \\
\hline \multirow[t]{2}{*}{$\begin{array}{l}\text { Other race, } \\
\text { non-Hispanic }\end{array}$} & & & & 0.228 & 0.230 \\
\hline & & & & $(0.163)$ & $(0.169)$ \\
\hline College degree & & & & $\begin{array}{c}0.027 \\
(0.089)\end{array}$ & $\begin{array}{c}0.033 \\
(0.090)\end{array}$ \\
\hline \multirow[t]{2}{*}{$\begin{array}{l}\text { Household income less } \\
\text { than } \$ 20,000\end{array}$} & & & & $-0.223^{*}$ & $-0.241 *$ \\
\hline & & & & $(0.128)$ & $(0.137)$ \\
\hline \multirow{2}{*}{$\begin{array}{l}\text { Household income } \\
\$ 20,000-35,000\end{array}$} & & & & $-0.250^{* *}$ & $-0.268 * *$ \\
\hline & & & & $(0.126)$ & $(0.126)$ \\
\hline \multirow{2}{*}{$\begin{array}{l}\text { Household income } \\
\$ 35,000-50,000\end{array}$} & & & & $-0.278^{* *}$ & $-0.290 * *$ \\
\hline & & & & $(0.123)$ & $(0.122)$ \\
\hline \multirow{2}{*}{$\begin{array}{l}\text { Household Income } \\
\$ 50,000-75,000\end{array}$} & & & & -0.129 & -0.135 \\
\hline & & & & $(0.116)$ & $(0.116)$ \\
\hline Married & & & & $\begin{array}{c}0.100 \\
(0.088)\end{array}$ & $\begin{array}{c}0.108 \\
(0.087)\end{array}$ \\
\hline Child in household & & & & $\begin{array}{r}-0.038 \\
(0.095)\end{array}$ & $\begin{array}{r}-0.010 \\
(0.095)\end{array}$ \\
\hline Household size & & & & $\begin{array}{l}-0.106^{* * * *} \\
(0.035)\end{array}$ & $\begin{array}{l}-0.111 * * * \\
(0.035)\end{array}$ \\
\hline Head of household & & & & $\begin{array}{c}-0.150 \\
(0.103)\end{array}$ & $\begin{array}{c}-0.117 \\
(0.107)\end{array}$ \\
\hline
\end{tabular}


The Geneva Risk and Insurance Review

134

Table 4 (continued)

\begin{tabular}{lccccc}
\hline Variable & Model 1 & Model 2 & Model 3 & Model 4 & Model 5 \\
\hline Home ownership & & & & -0.103 & -0.096 \\
& & & $(0.093)$ & $(0.086)$ \\
Sample size & 2,751 & 2,751 & 2,751 & 2,751 & 2,751 \\
Log likelihood & $-3,270.0$ & $-3,277.6$ & $-3,263.6$ & $-3,237.6$ & $-3,235.9$
\end{tabular}

Note: Bootstrapped standard errors (using 1,000 replicates) are in parentheses.

$* * *, * *$, and $*$ denote statistical significance from $\beta=0$ at 1,5 , and 10 per cent, respectively, based on likelihood ratio tests.

expectancy is associated with a 1.4 per cent increase in the odds of being in a more risk-tolerant group. The estimated coefficient for HUI score is 0.657 $(p<0.001)$ suggesting that each hundredth of a point increase in HUI score is associated with a 0.7 per cent increase in the odds of being in a higher risk-tolerance group.

Model 4 adds respondents' personal characteristics. Including the additional variables slightly increases the estimated coefficient of life expectancy and slightly decreases the estimated coefficient of health. The estimated coefficient on life expectancy is $0.019(p<0.001)$ suggesting that each additional year of life expectancy is associated with a 1.9 per cent increase in the odds of being in a higher risk-tolerance group. ${ }^{14}$ The estimated coefficient on HUI score is 0.517 ( $p=0.007)$ suggesting that each hundredth of a point increase in HUI score is associated with a 0.5 per cent increase in the odds of being in a more risk-tolerant group. Males are estimated to have 37 per cent greater odds of being in a higher risk-tolerance group than females $(p<0.001)$. Non-Hispanic Blacks are estimated to have 40 per cent greater odds of being in a higher risktolerance group than non-Hispanic Whites $(p=0.015)$. Respondents in larger households are estimated to be less risk tolerant, with the odds of being in a higher risk-tolerance group decreasing at a rate of 10 per cent per additional household member $(p=0.002)$. Estimated risk tolerance is not significantly associated with having a college degree $(p=0.767)$, marital status $(p=0.255)$, membership in a household with at least one child younger than 18 years ( $p=0.690)$, or identifying oneself as head of household $(p=0.146)$. The effect of home ownership is also not statistically significant $(p=0.269)$ although the negative sign of the estimated coefficient suggests that homeowners are less risk tolerant than other respondents.

\footnotetext{
${ }^{14}$ Adding a squared life expectancy term yields a small and statistically insignificant coefficient suggesting no significant departure from linearity.
} 
Relative risk tolerance is estimated to be a convex and weakly increasing function of household income. Compared with respondents in households earning more than $\$ 75,000$ per year, respondents in households earning less than $\$ 20,000$ are estimated to have 21 per cent lower odds of being in a higher risktolerance group $(p=0.083)$, respondents in households earning $\$ 20,000-35,000$ are estimated to have 24 per cent lower odds of being in a higher risk-tolerance group ( $p=0.048$ ), respondents in households earning $\$ 35,000-50,000$ are estimated to have 25 per cent lower odds of being in a higher risk-tolerance group $(p=0.024)$, whereas respondents in households earning $\$ 50,000-75,000$ do not statistically differ $(p=0.267)$. The increase in relative risk tolerance with income is similar to Guiso's and Paiella's (2001) finding that relative risk tolerance increases with wealth. The convexity of relative risk tolerance is consistent with our theoretical model: our empirical finding that risk tolerance increases with life expectancy implies that risk tolerance is convex in income Eq. (10). ${ }^{15}$

Model 5 is identical to Model 4 but replaces the variable for life expectancy with variables for age and age squared. The estimated coefficients for age and age squared are $-0.046(p<0.001)$ and $0.00031(p=0.028)$, respectively, suggesting that the odds of being in a more risk-tolerant group are a decreasing and convex function of age. As life expectancy is a decreasing and convex function of age in the U.S. population (Arias, 2006), the estimated coefficients for age and age squared in Model 5 are consistent with our finding that the odds of being in a more risk-tolerant group are a linear function of life expectancy. The estimated coefficient on male $(0.242, p<0.001)$ is somewhat smaller in Model 5 than in Model $4(0.314, p<0.001)$, consistent with the estimated positive relationship between life expectancy and risk tolerance (the coefficient on male in Model 5 compares risk tolerance of men to that of women of the same age, who have greater life expectancy). The estimated coefficients of the other variables have the same signs and similar magnitudes in both models.

\section{Sensitivity analysis}

Self-reported health is an important predictor of life expectancy (Mossey and Shapiro, 1982; Idler and Benyamini, 1997) but life tables stratified by health are not available. To explore how accounting for self-reported health in estimates of life expectancy might affect our previous results we calculate new estimates of life expectancy based on age, race, sex, and health category and re-estimate the regression models in Table 4 using the new estimates. Our adjustments for self-reported health category (i.e., excellent, very good, good,

\footnotetext{
${ }^{15}$ Note from Eq. (10) that $-v^{\prime}(y) / v^{\prime \prime}(y)$ is convex if and only if $\tau(\cdot)$ is convex.
} 
fair, poor) assume a constant proportional effect of health status on life expectancy (differentiated by sex) using estimates from Diehr et al. (1998). Using estimates of life expectancy based on self-reported health has virtually no effect on any of the estimated coefficients in the regression models. The one exception is the magnitude of the estimated coefficient for HUI score, which decreases slightly. For example, the estimated coefficient for HUI score in Model 3 decreases from 0.657 to $0.582(p=0.002)$ and the estimated coefficient for HUI score in Model 4 decreases from 0.517 to $0.489(p=0.016)$. The statistical significance of the coefficients remains largely unchanged.

In the contingent valuation literature, regression models of willingness to pay based on double-bounded, dichotomous-choice questions have been shown to produce more efficient estimates than those obtained using the singlebounded format (Hanemann et al., 1991; Alberini, 1995) but there is evidence that the initial bid may influence responses to follow-up questions (Alberini et al., 1997). The present study raises similar concerns by using doublebounded, dichotomous-choice questions to measure risk tolerance. To investigate the magnitude of any follow-up effect, we estimate the regression models in Table 4 using only the responses to the first question, which are used to place respondents into one of two groups that can be ordered by relative risk tolerance. These single-bounded models yield qualitatively similar results to the double-bounded models in Table 4 suggesting that any follow-up effect does not substantially influence our findings.

\section{Conclusion}

In a survey of the general U.S. population, we find that tolerance of income risk is positively related to both health and expected longevity. Our empirical results depart from theoretical predictions of the additive life-cycle model with standard (HARA) parametric utility functions (e.g., logarithmic and power functions) and with a multiplicative form for the instantaneous utility function of consumption and health (see Eq. (12)). These models imply that health and longevity do not affect risk tolerance. In contrast, our empirical results imply that the relative risk tolerance of instantaneous utility is not linear but convex and weakly increasing in income, and so the commonly assumed HARA specifications of the utility function may inappropriately constrain the roles of health and longevity. ${ }^{16}$ In both our theoretical and empirical work, we consider

\footnotetext{
${ }^{16}$ Recall that we have based our analysis on the strong assumption that expected health and longevity are exogenous. In the non-additive model of Bommier and Rochet (2006), increasing risk tolerance with life expectancy implies that consumption levels at different dates are specific complements.
} 
risks to income, not wealth, and examine risks to lifetime income that take the form of perfectly correlated risks to income in each period with uncertainty resolved early in life. When income risks are not perfectly correlated between periods, the timing of the resolution of risks can influence attitudes toward future risks (Eeckhoudt et al., 2005).

Our results describe correlations and may not reflect causation. For example, the positive association between life expectancy and risk tolerance may be influenced by factors for which we have no data, such as availability of health insurance: individuals with better health insurance may be more tolerant of other financial risk (because they face smaller risk of high medical expenses) and have greater life expectancy (because they have better access to health care). Nevertheless, our results may have implications for future research on health, aging, retirement, consumption, and investment decisions. Given that older individuals are more likely to suffer poor health and to control a disproportionate share of wealth and insurance products, greater attention should be given to the influence of health and longevity on financial behaviour.

\section{Acknowledgements}

This work was supported in part by the Economic Research Service of the United States Department of Agriculture and the Pierre-de-Fermat Chaire d'Excellence at the Toulouse School of Economics. It was presented at the European Group of Risk and Insurance Economists seminar, Stockholm School of Economics, Université Catholique de Lille, and GREQAM (Marseille). We thank seminar participants, Antoine Bommier, Nicolas Drouhin and the referees for helpful comments.

\section{References}

Alberini, A. (1995) 'Efficiency vs. bias of willingness-to-pay estimates: Bivariate and interval-data models', Journal of Environmental Economics and Management 29: 169-180.

Alberini, A., Kanninen, B. and Carson, R.T. (1997) 'Modeling response incentive effects in dichotomous choice contingent valuation data', Land Economics 73: 309-324.

Arias, E. (2006) United States life tables, 2003 National Vital Statistics Reports 54(14), National Center for Health Statistics, Hyattsville, Maryland.

Barsky, R.B., Juster, F.T., Kimball, M.S. and Shapiro, M.D. (1997) 'Preference parameters and behavioral heterogeneity: An experimental approach in the health and retirement study', Quarterly Journal of Economics 112: 537-580.

Benitez-Silva, H. and Dwyer, D.S. (2005) 'The rationality of retirement expectations and the role of new information', Review of Economics and Statistics 87: 587-592.

Bleichrodt, H. and Quiggin, J. (1999) 'Life-cycle preferences over consumption and health: When is cost-effectiveness analysis equivalent to cost-benefit analysis?' Journal of Health Economics 18: 681-708.

Bommier, A. and Rochet, J.-C. (2006) 'Risk aversion and planning horizons', Journal of the European Economic Association 4: 708-734. 
Diehr, P., Patrick, D.L., Bild, D.E., Burke, G.L. and Williamson, J.D. (1998) 'Predicting future years of healthy life for older adults', Journal of Clinical Epidemiology 51: 343-353.

Dohmen, T., Falk, A., Huffman, D., Sunde, U., Schupp, J. and Wagner, G.G. (2005) Individual risk attitudes: New evidence from a large, representative, experimentally-validated survey, discussion paper 1730, Institute for the Study of Labor (IZA).

Domeij, D. and Johannesson, M. (2006) 'Consumption and health', B.E. Journals in Macroeconomics: Contributions to Macroeconomics 6: 1-30.

Edwards, R.D. (2008) 'Health risk and portfolio choice' Journal of Business and Economic Statistics 26: $472-485$.

Eeckhoudt, L., Gollier, C. and Treich, N. (2005) 'Optimal consumption and the timing of the resolution of uncertainty', European Economic Review 49: 761-773.

Engen, E.M., Gale, W.G. and Uccello, C.E. (1999) 'The adequacy of retirement saving', Brookings Papers on Economic Activity 2: 65-187.

Evans, W.N. and Viscusi, W.K. (1991) 'Estimation of state dependent utility functions using survey data', Review of Economics and Statistics 73: 94-104.

Feeny, D., Furlong, W., Torrance, G.W., Goldsmith, C.H., Zhu, Z., DePauw, S., Denton, M. and Boyle, M. (2002) 'Multiattribute and single-attribute utility functions for the health utilities index mark 3 system', Medical Care 40: 113-128.

Finkelstein, A., Luttmer, E.F.P. and Notowidigdo, M.J. (2008) What good is wealth without health? The effect of health on the marginal utility of consumption, NBER working paper 14089.

Garber, A.M. and Phelps, C.E. (1997) 'Economic foundations of cost-effectiveness analysis', Journal of Health Economics 16: 1-31.

Gollier, C. (2001) The Economics of Risk and Time, Boston: MIT Press.

Gollier, C. (2002) 'Time diversification, liquidity constraint, and decreasing aversion to risk on wealth', Journal of Monetary Economics 49: 1439-1459.

Gollier, C. and Pratt, J.W. (1996) 'Risk vulnerability and the tempering effect of background risk', Econometrica 64: 1109-1123.

Guiso, L., Jappelli, T. and Terlizzese, D. (1996) 'Income risk, borrowing constraints, and portfolio choice', American Economic Review 86: 158-172.

Guiso, L. and Paiella, M. (2001) 'Risk aversion, wealth and background risk', discussion paper 2728, Center for Economic Policy Research.

Hammitt, J.K. (2002a) 'QALYs versus WTP', Risk Analysis 22: 985-1001.

Hammitt, J.K (2002b) How Much is a QALY Worth? Admissible Utility Functions for Health and Wealth, working paper, Harvard Center for Risk Analysis, Boston.

Hanemann, W.M., Loomis, J. and Kanninen, B. (1991) 'Statistical efficiency of double-bounded dichotomous choice contingent valuation', American Journal of Agricultural Economics 73: 1255-1261.

Idler, E.L. and Benyamini, Y. (1997) 'Self-rated health and mortality: A review of twenty-seven community studies', Journal of Health and Social Behavior 38: 21-37.

Karlsson, A. (2006) Time Diversification in Pension Savings, working paper, Stockholm University School of Business, Stockholm.

Kimball, M.S. (1993) 'Standard risk aversion', Econometrica 61: 589-611.

Lillard, L.A. and Weiss, Y. (1997) 'Uncertain health and survival: Effects on end-of-life consumption', Journal of Business and Economic Statistics 15: 254-268.

Mossey, J.M. and Shapiro, E. (1982) 'Self-rated health: A predictor of mortality among the elderly', American Journal of Public Health 72: 800-808.

Murphy, K.M. and Topel, R.H. (2006) 'The value of health and longevity', Journal of Political Economy 114: 871-904.

Nordhaus, W.D. (2002) The health of nations: The contribution of improved health to living standards, National Bureau of Economic Research working paper 8818. 
Palumbo, M.G. (1999) 'Uncertain medical expenses and precautionary savings near the end of the life-cycle', Review of Economic Studies 66: 386-421.

Picone, G., Sloan, F. and Taylor Jr., D. (2004) 'Effects of risk and time preferences and expected longevity on demand for medical tests', Journal of Risk and Uncertainty 28: 39-53.

Pratt, J.W. and Zeckhauser, R.J. (1987) 'Proper risk aversion', Econometrica 55: 143-154.

Rey, B. and Rochet, J.-C. (2004) 'Health and wealth: How do they affect individual preferences?' Geneva Papers on Risk and Insurance Theory 29: 43-54.

Samuelson, P. (1963) 'Risk and uncertainty: A fallacy of large numbers', Scientia 98: 108-113.

Shepard, D.S. and Zeckhauser, R.J. (1984) 'Survival versus consumption', Management Science 30: 423-439.

Sloan, F.A., Viscusi, W.K., Chesson, H.W., Conover, C.J. and Whetten-Goldstein, K. (1998) 'Alternative approaches to valuing intangible health losses: The evidence for multiple sclerosis', Journal of Health Economics 17: 475-497.

Smith, J.E. and Keeney, R.L. (2005) 'Your money or your life: A prescriptive model for health, safety and consumption decisions', Management Science 51: 1309-1325.

Torrance, G.W., Feeny, D.H., Furlong, W.J., Barr, R.D., Zhang, Y. and Wang, Q. (1996) 'Multiattribute utility function for a comprehensive health status classification system: Health utilities index mark 2', Medical Care 34: 702-722.

Viscusi, W.K. and Evans, W.N. (1990) 'Utility functions that depend on health status: Estimates and economic implications', American Economic Review 80: 353-374.

Wilson, R. (1968) 'The theory of syndicates', Econometrica 36: 113-132.

Yaari, M.E. (1965) 'Uncertain lifetime, life insurance, and the theory of the consumer?' Review of Economic Studies 32: 137-150.

\section{About the Authors}

James K. Hammitt is Professor of Economics and Decision Sciences and Director of the Harvard Center for Risk Analysis. He held the Pierrede-Fermat Chaire d'Excellence at the Toulouse School of Economics in 2005-2006.

Kevin Haninger is AAAS Science \& Technology Policy Fellow at the U.S. Environmental Protection Agency. He was a post-doctoral fellow at the Toulouse School of Economics in 2006.

Nicolas Treich is Research Director at the Toulouse School of Economics (LERNA, INRA). 